\title{
Optimal urban density for a carbon free city in different climates
}

\author{
Udo Dietrich, Hsiao-Hui Chen \\ REAP Research Group, HafenCity University Hamburg, Hamburg, Germany \\ E-mail: udo.dietrich@hcu-hamburg.de,hsiao-hui.chen@hcu-hamburg.de
}

\begin{abstract}
In a carbon free city, the energy demand, including thermal energy (heating, cooling and hot water), power (ventilation and artificial light) in buildings and transport, need to be covered by the renewables gained on site or in the surrounding area outside of the town. This means a huge compensating area is required for harvesting renewable energy. This paper aims to explore the urban density that could potentially achieve the balance among three requirements: energy saving, land saving, and human scale. By holding constant of building type, number of inhabitants, thermal energy system, power harvesting system, lighting system, traffic energy (electric car), and street width of $25 \mathrm{~m}$, different scenarios of urban densities in various climate zones were compared. The results show that, although increasing urban densities by increasing number of storeys does reduce transportation energy consumption, the rate of decreased transportation energy consumption slows down as the number of storeys increases. Also, artificial light will reach saturation $(100 \%$ of hours of use) with increased number of storeys and, therefore, increase building energy consumption. For cold or moderate climates, the optimal scenario would be 4 to 6 storeys. For the hot and humid climates, the optimal choice would be 6 to 8 storeys. These optimal ranges of number of storeys provide good daylight access and also fall into the range of human scale.
\end{abstract}

Keywords: Zero Energy Building, compensating measure, urban densities, energy demand, land-use requirement

\section{Introduction}

The Paris Climate Conference in 2015, also known as COP 21, aims to achieve a legally binding and universal agreement on climate with the aim of keeping global warming below 2 degrees. To achieve this goal, cities will be key to a sustainable energy transition. This means our cities need to replace thermal energy (heating, cooling, and hot water) and power (ventilation, artificial light) in buildings and traffic with the renewable energy.

However, a critical challenge is that reaching the renewable targets is not always on the top of the priority list in the land-use planning process. Different aspects of urban development are competing with each other for more space and they are often contradicting with each other. For example, although larger number of storeys creates more area of use and reduces the demand for traffic energy, it also leads to less daylight and solar access to facades and increases the energy demand on lighting and heating. And the increasing demand for renewable energy also faces the challenge of increasing need of addition land outside of the city for harvesting renewable energies with wind turbines, PV modules, sustainable agriculture, and etc. The additional land outside of the city is referred to as the compensating land.

Also, higher buildings often do not fall into 
the range of a human scale neighbourhood. Therefore, finding an optimal urban density, which is defined as floor area ratio (FAR) or plot ratio, and land-use planning that could balance different development targets is a crucial step in the development a carbon free city. However, to date, most papers deal with only one specific aspect of carbon free city and there have not been many studies that include both the considerations of human scale and the land-use requirement of Zero Energy Building (Chen and Dietrich, 2016).

This paper aims to answer the following question in order to contribute to the discussion by considering multiple aspects of urban planning in the process of developing a carbon free city.

Which urban density is the optimal one that meets the requirement of energy saving, land saving, and human scale in developing carbon free cities?

Do results differ in different climates?

\section{Methods, assumptions and measurements}

For all calculations we assumed an optimized situation of the cities that should hopefully be fulfilled in the near future between 2030 and 2050. Today's urban planning should include these findings so that no further obstacle is created for meeting the goal of COP 21.

The buildings have a minimized demand for thermal energy:

For cold and moderate climates, such as Hamburg, a passive house is assumed. For 6 months per year, mechanical ventilation with heat recovery is needed. For 6 month per year, the building is naturally ventilated. According to an external shading system, a moderate window size and intelligent ventilation strategy are use. There is no cooling demand.

For hot and humid climates, such as Singapore, cooling demand is minimized by an external shading system, a moderate window size and an intelligent ventilation strategy. Air conditioning is running 12 month a year. There is no heating demand.

Energy demand for hot water is assumed to be constant for both locations.

For optimal daylight access the building depth is assumed with $14 \mathrm{~m}$. The building distance is set to $25 \mathrm{~m}$ what corresponds to a good standard street width. Artificial light is assumed with $11 \mathrm{~W} / \mathrm{m}^{2}$ (energy saving bulbs). For traffic it is assumed that the whole fleet of cars has changed from combustion to electrical engines.

All thermal energy is covered by a geothermal system (on-site on the estate) with a heat pump (HP). If the size of the estate is not sufficient for heat pump to meet the heating demand, compensating land is required and here the wood pellets are taken into account as an example. Similarly, if the size of the estate is not sufficient for heat pump to meet the cooling demand, a power driven split device is used.

All power demand (heat pump, split device, ventilation, electrical equipment, artificial light, traffic) is covered by PV-modules mounted on the building's roof. If this is not sufficient, one of the options is to install wind turbines for power production on compensating land outside of the city.

All building related energy demands were simulated with energy plus based software (PRIMERO-COMFORT, 2009). The effect of increasing power demand for artificial light as a consequence of shadowing from neighboured buildings is included.

To facilitate the task it is assumed that the thermal energy demand does not change with the building's shape and number of storeys. As a consequence the only changing energy demands are the ones for traffic and artificial light. The energy demand for traffic is estimated on basis of the work of Newman and Kenworthy (1999)(see figure 3). Their famous hyperbola describes the decreasing energy demand for traffic with increasing urban density.

In the following investigations twenty different scenarios of urban densities were created by changing the number of storeys. Table 1 presents these scenarios. The main target is to compare the building energy demand and the land-use requirement for estate as well as for compensating land in various climate zones. Different urban densities are simulated by varying the number of stories from one to twenty. The energy demand and the land-use requirement for estate and compensating land are compared. All results are related to 100 inhabitants. 


\section{Result and analysis Energy demand}

The power demand has its basis on the constant values for heating, cooling, hot water, equipment and mechanical ventilation. The power demand for artificial light and traffic varies with the urban density (and thus the number of storeys), they have to be added to the total power demand.

In general, the power demand for traffic decreases rapidly with increasing urban densities but for larger urban densities the effect becomes smaller. Power demand for artificial light increases linearly with urban density. It reaches its maximum at urban density 4.3 (with the assumed $25 \mathrm{~m}$ street width that corresponds to 4 storeys) and does not increase further because the light already needs to be switched on all the time. That leads finally to a minimum in power demand at a certain urban densities. And this number varies in different climates. The detailed investigation is presented in the following.

\section{Percentage of detailed energy demand Cold or moderate cimate}

The results in figure 2 and 3 also indicate that the effect of increasing urban densities on different energy demands is positive on artificial light and negative on traffic. The energy demand for artificial light increases with urban densities, while the energy demand for traffic decreases with urban densities. But this effect gradually becomes weaker and weaker as the urban densities increases. More specifically, when the urban density is larger than 1.43 (with the assumed $25 \mathrm{~m}$ street width that corresponds to 4 storeys), the demand for traffic energy slows down as the building becomes higher. Therefore, when the building height is larger than 4 storeys, artificial light becomes the dominant influence on the total energy demand

Furthermore, when the building height is taller than 8 storeys, urban density starts to exert effect on energy demand for heat pump for heating and hot water. This is due to the fact that, when the urban densities are larger than 2.87 (with the assumed $25 \mathrm{~m}$ street width that corresponds to 8 storeys), the whole estate is used up for heat exchangers. Additional compensating land is required to harvest more energy produced by wood pellets. When the urban density are larger than 6.10 (with the assumed $25 \mathrm{~m}$ street width that corresponds to 17 storeys), more than half of the energy demand for heat pump for heating and hot water is produced on the compensating land.

\section{Hot and humid climate}

Comparing with Hamburg, the demand for artificial light in general is lower in Singapore because there is more daylight during the hours of usage. When the urban density is larger than 4.31 (with the assumed $25 \mathrm{~m}$ street width that corresponds to 12 storeys), the power for cooling starts to increase with urban densities. Since power for cooling is supplied by HP and supplementary power for split device and HP is a constant value up to 12 storeys, the supplementary power for split device is required when the building is taller than 12 storeys. Because the estate area onsite is already fully used for HP for cooling.

\section{Land-use demand \\ Total demand of land \\ Cold or moderate climate}

Figure 4 shows that the urban density of 0.72 (with the assumed $25 \mathrm{~m}$ street width that corresponds to 2 storeys) requires the least land for estate and compensating measure. The land-use requirement for 2-storey building is even smaller than 1 storey buildings. When the building is higher than 2 storeys, the required land increases. The speed of increase becomes even faster when the building is higher than 8 storeys.

Further detailed results in figure 4 of about the land-use demand in estate, compensating land for power and heating provide the explanation. When the buildings are taller 
than 2 storeys, additional compensating land is required to produce energy for power demand. When the buildings are taller than 8 storeys, the whole estate is used up for heat exchangers. Additional compensating land is required to harvest more energy produced by wood pellets for heating demand. Since the energy density of wood pellets is smaller than the one of heat pump, much larger area of land for wood pellets is required off-site.

\section{Hot and humid climate}

Comparing with cold or moderate climates, a building with 3 storeys, instead of 2 storeys, requires the least land for estate and compensating measure in hot and humid climates. The land use requirement for 3-storey building is even smaller than 1- and 2-storey buildings. When the building is higher than 3 storeys, the required land increases and the speed of increase gradually slows down. There is a further slow-down when the building is taller than 12 storeys because there is no further increase in power demand for artificial light.

Further detailed results in figure 4 of about the land-use demand in estate, compensating land for power and heating provide the explanation. When the buildings are taller than 3 storeys, additional compensating land is required to produce energy for power demand. The power demand increases linearly until 12 storeys (corresponding to a ratio building distance to building height of 0.65 ) and when the building is taller than 12 storeys, the artificial light reaches its maximum because the light is always switched on and there will be no further increase with the urban densities.

Effect of alternative energy harvesting technologies (PV) on the compensating land In this section, the results of land-use demand for choosing PV as an alternative energy harvesting technology are provided as a reference for comparison with that produced by wind turbines.

\section{Cold or moderate climate}

Figure 5 shows that, if the power is produced with PV on the off-site compensating measure, a 7-storey building and a typical street with the width of $25 \mathrm{~m}$ is the most land-use saving choice. When the urban density are larger than 2.51 (with the assumed $25 \mathrm{~m}$ street width that corresponds to 7 storeys), there start to show a rapid growth of land-use demand because of the low energy density of compensating measures using wood pellets for heating.

\section{Hot and humid climate}

Figure 5 also shows that, if the power is produced with $\mathrm{PV}$ on the off-site compensating measure, the higher the building the more land-use saving it is in hot and humid climates. However, the advantage becomes small when the number of storey is larger 6 to 8 storeys. Therefore, it is recommended to stay in human scale. There is no need for compensating measures for heating and only the need for compensating measures for power. The energy density of PV on buildings roofs and on land outside of town are identical. Therefore, the decreasing land-use demand can be explained by the increasing urban densities.

Comparing the energy harvesting technologies used in the city center and the one used outside of the city, the later has stronger influence on the final results of the off-site land-use demand. In other words, if the energy density of the renewable systems on site is higher than the one off site, the total need of land grows rapidly with growing urban densities. Because the land where high energydensiy systems could be used becomes smaller. Thus, renewable energy production will be a mix of all available technologies. For example, the current distribution of the renewable power production in Germany is $20 \%$ of $\mathrm{PV}, 14 \%$ of water, $31 \%$ of biomass, and $35 \%$ of wind.

In the city center, we can choose the system with high energy density, such as geothermal and heat pump for thermal energy and PV modules on the building's roofs. Outside of town, this becomes more difficult. Thermal energy cannot be transported over long distances (district heating/cooling) only as material to burn (wood pellets, renewable gas etc). Such a production has a very low 
energy density. PV has the highest energy density but it is not a good idea to cover the whole land outside of town with PV-modules because that would hinder any other use, such as monocultural agriculture, and creates a competition with food production. The best place for PV modules would be on the building's roofs and in the desert from where power is sold to users. Furthermore, if we place wind turbines onshore, the land could be used furthermore for agriculture. If we place PV modules, the land could not be used for other purposes. In short, the value of compensating land is different when the multiple functions of land-use is taken into consideration.

\section{Conclusion and recommendation}

In this paper, different scenarios were created to explore the relationship between urban density, energy demand, and land-use demand. This research also compares this relationship in different climate zones using different energy harvesting technologies. The results show that low-rise buildings with high density may be an optimal option. It is suggested that the land-use planning for renewable energy must measure energy density as well as consider the amount of land required by different building designs. This research highlights the importance of land-use policy and the need for urban policy to create a more holistic view by including a land-use requirement for energy harvesting.

With regard to the development of renewable energies, our future must be based on power. Such systems have the highest energy density. With regard to the guidelines for sustainable urban development: use the minimal urban densities $1.0(100 \mathrm{inh} / \mathrm{ha})$ so that it stay in the lower part of Newman-Kenworthy hyperbola and create an energy efficient traffic system based on tram, subway, bus etc. avoid too high urban densities, as they do not reduce energy demand remarkably but influence daylight access and human scale negatively building heights should be in the same range to avoid shadowing of roofs for renewable energy systems on site, choose the one with the highest efficiencies, such as geothermal or PV modules on building's roofs select compensating measures carefully so that there is no competition between harvest of renewable energies and food production, need of forests etc. 


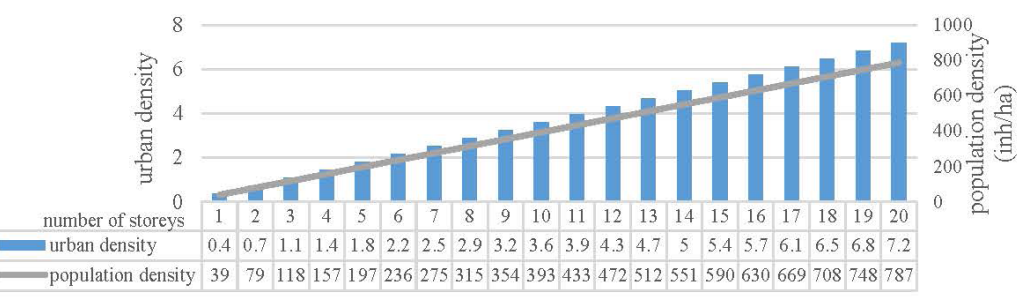

Figure 1 Twenty scenarios with different urban density and population density by number of storeys

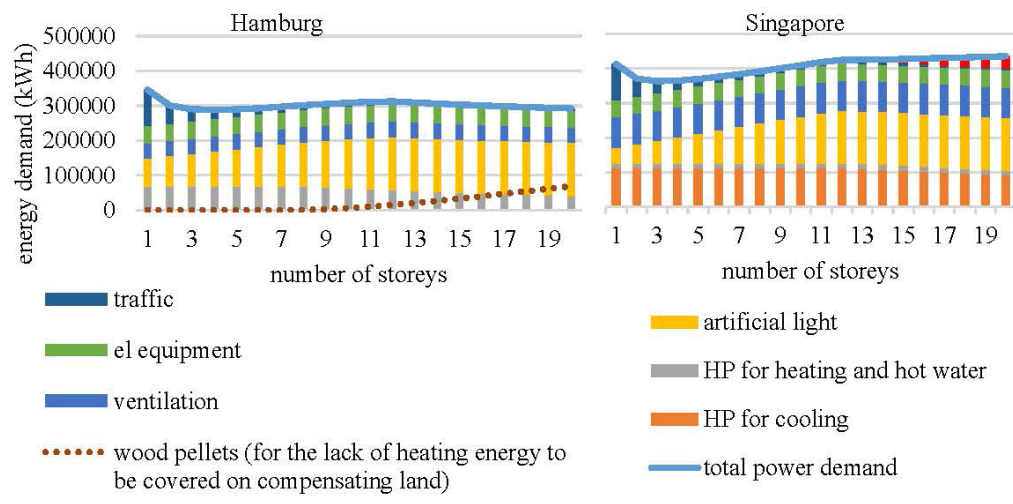

Figure 2. Energy demand of different categories in Hamburg and Singapore.
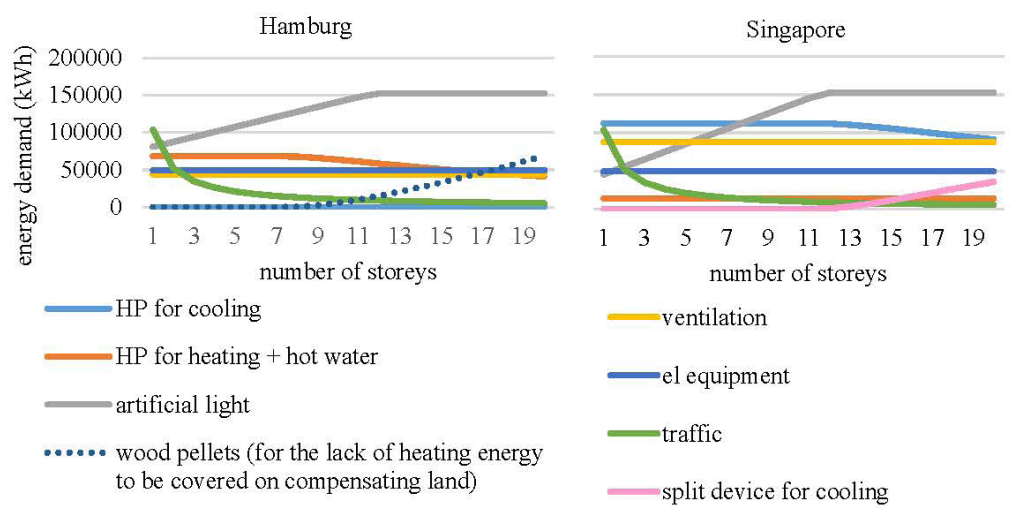

Figure 3. The detailed comparison of energy demand of different categories in Hamburg and Singapore. 


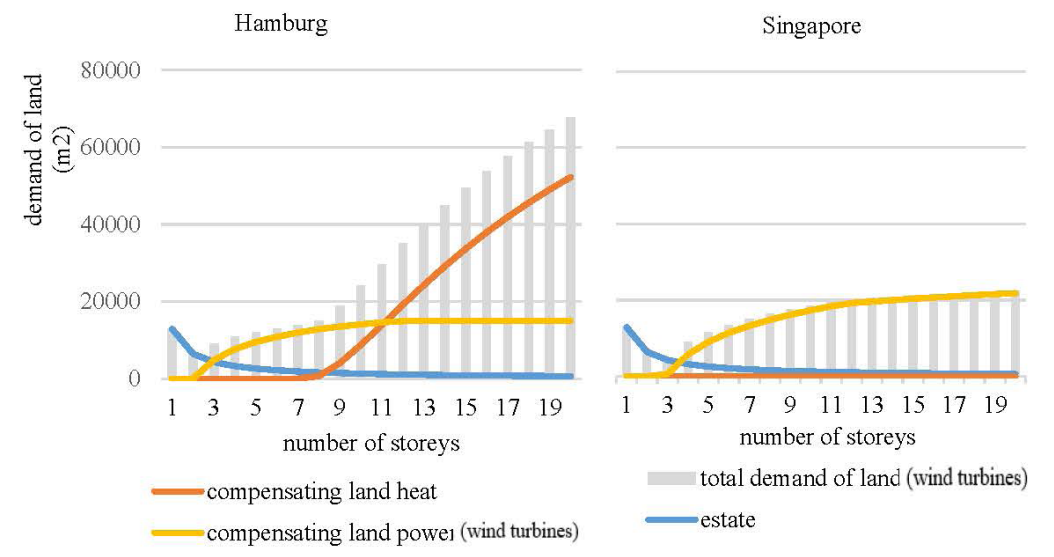

Figure 4. Effect of urban densities on the total demand of land and the detailed comparison of the land-use demand in estate and compensating land for power and heating in Hamburg and Singapore.
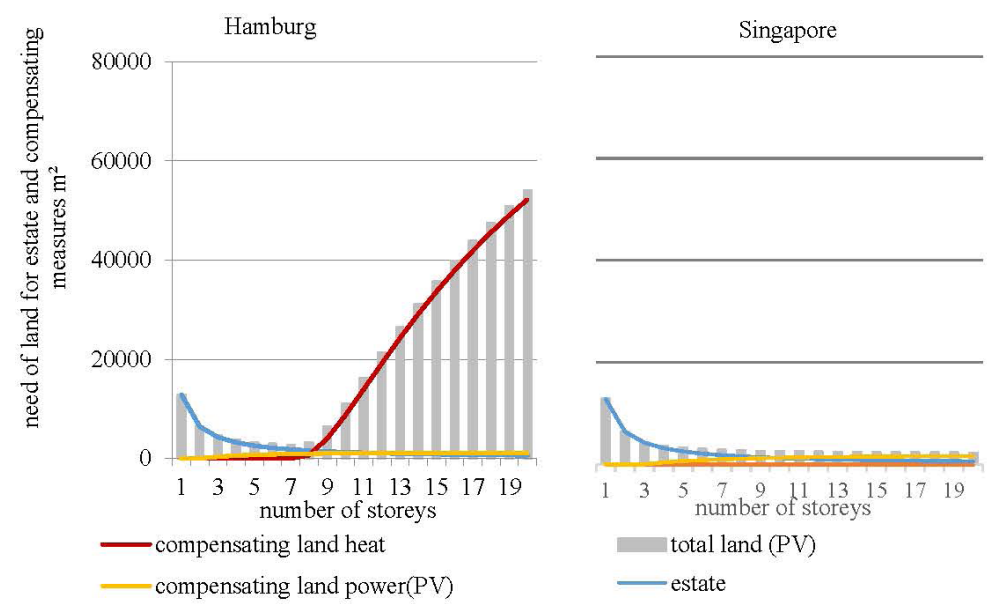

Figure 5. The need of land for estate and compensating measures to produce power with PV. 


\section{References}

Chen, H.-H. and Dietrich, U. (2017). Landuse planning for Zero-Energy-Buildings: comparison of 4 high-density cities. Sustainable City 2017- 2th International Conference on Urban Regeneration and Sustainability. Seville, Spain.

Chen, H.-H. and Dietrich, U. (2016). Potential and risk for (nearly)-Zero-Energy-Buildings under defined urban densities: The case of Singapore. Hamburg: SBE 16-International Conference on Sustainable Built Environment.

MacKay, D. (2009). Sustainable Energy without the hot air. Tratto da UIT Cambridge, ISBN 978-0-9544529-3-3. Retrived from www.withouthotair.com

Newman, P. and Kenworthy, J. (1999). Sustainability and Cities: Overcoming Automobile Dependence. Washington DC: Island.

PRIMERO-COMFORT. (2009). Retrieved from PC-program developed by $\mathrm{HCU}$ Hamburg, promoted by Rud. Otto Meyer-Umwelt-Stiftung. Tratto da www. primerosoftware.de

Ratti, C., Bakerb, N., and Steemers, K. (2005). Energy consumption and urban texture. Energy and Buildings, 35(7), 762-776. doi:10.1016/j. enbuild.2004.10.010.

Salat, S. (2009). Energy loads, CO2 emissions and building stocks: morphologies, typologies, energy systems and behaviour. Building Research and Information, 37(5-6), 598-609. doi: 10.1080/09613210903162126.

Salat, S. (2011). Cities and Forms: On Sustainable Urbanism. Paris: CSTB Urban Morphology Laboratory. 